\title{
Using Native Vegetation Screens to Lessen the Visual Impact of Rural Buildings in the Sierras de Béjar and Francia Biosphere Reserve: Case Studies and Public Survey
}

\author{
Jacinto Garrido Velarde ${ }^{1, *}$, María Jesús Montero Parejo ${ }^{2} \mathbb{0}$, Julio Hernández Blanco ${ }^{2} \mathbb{C}$ and \\ Lorenzo García Moruno ${ }^{3}$ \\ 1 Department of Territorial Sciences, University of Extremadura, 10003 Cáceres, Spain \\ 2 Department of Graphical Expression, University of Extremadura, 10600 Plasencia, Spain; \\ cmontero@unex.es (M.J.M.P.); juliohb@unex.es (J.H.B.) \\ 3 Department of Graphical Expression, University of Extremadura, 06800 Mérida, Spain; igmoruno@unex.es \\ * Correspondence: jgvelarde@unex.es or jgarridoif@gmail.com; Tel.: +927-25-70-00
}

Received: 13 March 2019; Accepted: 29 April 2019; Published: 6 May 2019

\begin{abstract}
Tree screens have a demonstrated role in lessening the visual impact of buildings nonintegrated aesthetically by means of filtering façades. This is particularly useful on village fringes and in areas bordering urban green spaces. However, the role of other vegetal structure such as climber species, and their optimal percentage for façade filtering, have not been measured yet. The main objectives of present study were: (1) To guess if climber species have a similar positive role to lessen the visual impact of a façade than tree species, and (2) to compare optimal percentage of coverage for both vegetal structures. To explore them, we designed three percentages of partial-concealment vegetation screens ( $0 \%$ none, $40-50 \%$ medium, $70-80 \%$ high), comprising tree or climber native species from a study area, in eight buildings from the same region. As a result, 24 final infographics were evaluated by two groups of interviewees: 27 local people and 39 non-local university students. Respondents had to assess the integration of the building in terms of visual preference using an ascending scale with 5 options from "Very poor" $=1$ to "Very good" $=5$. The results show a clear linear positive response of participants when increasing the percentage of coverage by both types of vegetal screens. However, positive significant valuation over 3 points on average was reached before in tree species screens (3.06, in $40-50 \%$ of façade coverage) than in climbing species screens (3.02 in 70-80\% of façade coverage). Finally, there was a high consensus in responses when both groups polled were compared.
\end{abstract}

Keywords: borderland; cross-border; landscape; buildings; native vegetation; vegetation screens; visual impact

\section{Introduction}

The need to minimize the visual impact of buildings on the landscape is imposed by society's growing awareness of environmental respect and conservation in recent years [1-3]. In urban environments, this task has been partially achieved by the particular characteristics of built landscapes that are able to absorb negative impacts in a way which, paradoxically, could be defined as "natural". However, in rural environments, there is clearly a need to maintain the functionality of this space, while also attempting to reduce as far as possible the perception of the effects of building development and human action on the landscape [4-6]. The emergence of new construction materials and techniques has led to a proliferation of buildings which, in many cases, fracture the harmony of a landscape that 
society considers natural and had remained so for many years. The current approach is to integrate buildings into the aesthetics of the rural environment to harmonize the two concepts $[7,8]$.

From an architectural point of view, vegetation offers a multitude of options for creating more comfortable and aesthetically pleasing spaces around buildings [9-13]. Vegetation is used to complement the design of bioclimatic houses, particularly in countries with many hours of sunlight and high summer temperatures [14-16]. It can also be used as a tool to improve the visual relationship between a building and its surroundings by softening the cognitive reading of visual variables of the building, such as lines, forms, and scale [17], or aesthetic variables, including colors and textures [18-20]. Vegetation is therefore one of the most important external parameters in building integration analysis.

Since the 1980s, several authors have examined the role of vegetation in the perception and aesthetics of the environment [21-24]. The use of vegetation screens to reduce the visual impact of buildings has been widely studied as an option to improve the visual acceptance of a building. This is especially important when, due to the building's morphological features (shape, height, materials, etc.), effective integration into the landscape is not possible [25].

Vegetation has not always been studied explicitly, but rather indirectly, through associated concepts. "Mystery", defined as the promise of new information if one could travel deeper into the environment, has been studied by several authors [26-29]. Although this definition is subjective, it is directly related to the degree to which the scene is concealed or filtered by natural elements such as vegetation. Studies have shown how, together with topography, the amount of vegetation concealing a scene is relevant in determining the visual quality and quantity of the observed landscape [30]. Ikemy [29] made a preliminary study of the degree or amount of filtering by trees in frontal planes to a building as an integration tool, establishing filtering thresholds (low to high) without numerical quantification. Other studies have analyzed percentages of filtering in frontal planes of buildings [31].

Screens can be used to either totally or partially conceal a building. Total concealment of a building by vegetation screens is an interesting option when, due to the morphological characteristics of the building (form, height, materials, etc.), effective integration into the landscape is impossible [25]. However, other researchers concluded that total concealment of a scene may be counterproductive, because the human brain needs to complete the visual information of the concealed elements (e.g., the building) to satisfy the mystery of a hidden object [30]. A partial-concealment vegetation screen appears to be the best solution to improve the perception of some defining features of a building, such as line, form, and scale [32].

Barriers should be of appropriate size and foliage density to partially conceal lines and forms [33]. If necessary, plant screens can be suitably staggered, using tree and bush species native to the area of varying size, foliage density and growth rate [22]. Screens should be placed in front of or behind edges, such as the ends of a building, to avoid the cut-out effect against the skyline. Adding natural vegetation elements whose forms have a similar orientation to that of the building achieves better integration with the surroundings by reducing contrasts.

Much work remains in the analysis of the design of buildings targeted for improved integration using vegetation. Other aspects, such as species type and layout in the foreground of a building and the degree of filtering, require further investigation to achieve satisfactory building integration.

The main objective of this work is to determine how varying the percentage of a building covered by vegetation screens can affect the visual perception and evaluation of the building in its immediate surroundings. Digital image analysis techniques are applied, as well as scenario simulation using real photos, working with several practical cases chosen in Northwest Spain and simulating a range of filtering percentages with varying vegetation types on the initial buildings. 


\section{Study Area}

\subsection{Description of the Study Area}

The study was conducted in the Sierras de Béjar y Francia Biosphere Reserve (Figure 1), in the Northwest Iberian Peninsula (UNESCO 2017). Despite Euro-Siberian influences, the reserve is part of the Mediterranean region and includes 88 municipalities in an area of 199,140 hectares. Zoning of the area is shown in Table 1.

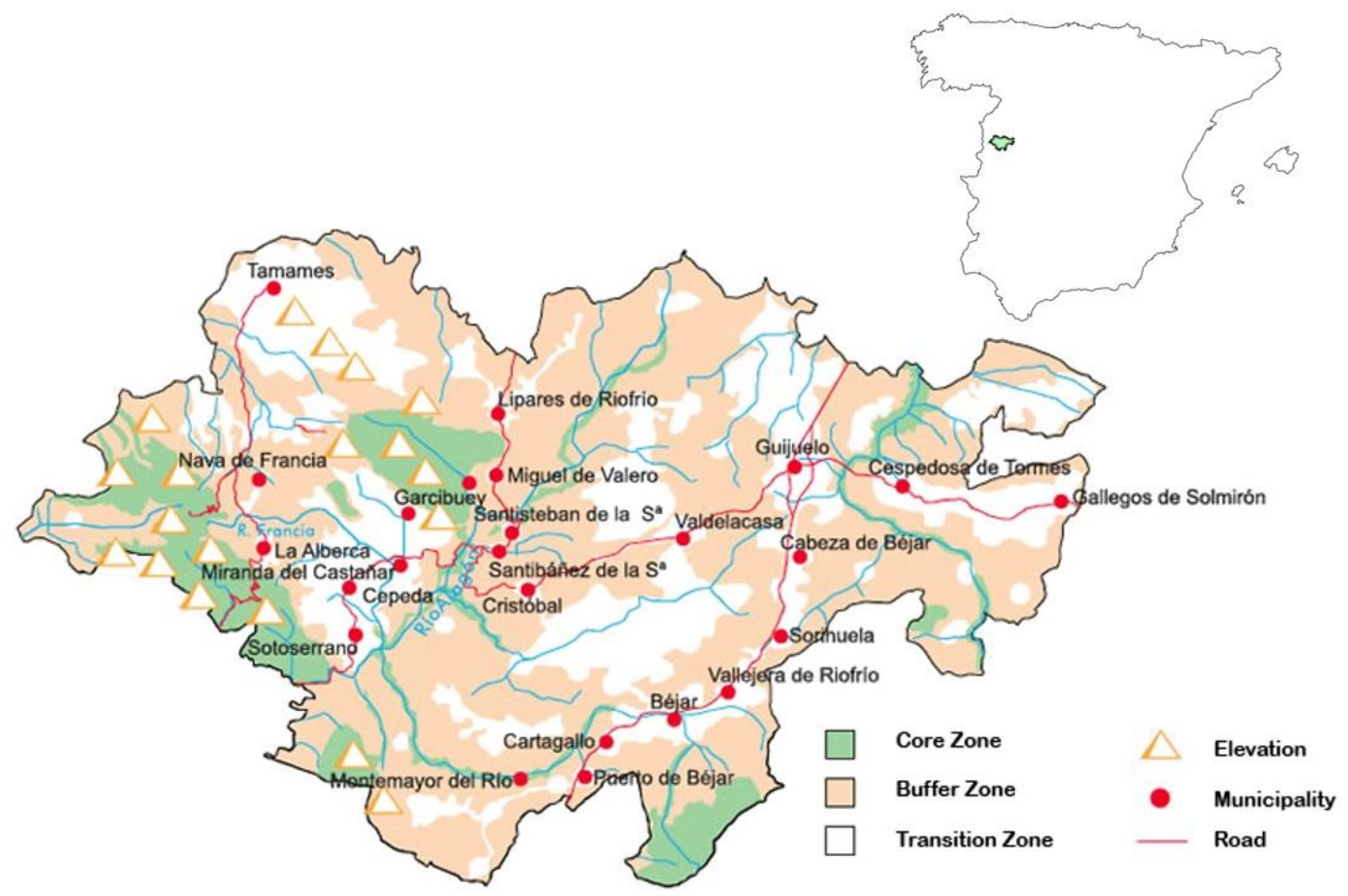

Figure 1. Location of Las Sierras de Béjar y Francia Biosphere Reserve. Source: UNESCO. Spanish Committee of the MaB.2006 program. National Geographic Institute.

Table 1. Zoning of the Sierras de Béjar y Francia Biosphere Reserve.

\begin{tabular}{ccc}
\hline Zoning & ha & \% \\
\hline Core Zone & 24,385 & 12.24 \\
Buffer Zone & 113,197 & 56.84 \\
Transition Zone & 61,558 & 30.91 \\
\hline
\end{tabular}

The core zone comprises the most representative areas of the reserve. Little used by humans, it is not subjected to activities of great environmental impact and contains no human settlements. The buffer zone surrounds the core zone and similarly includes no settlements, although it is constantly used by humans for the main economic activities of the area: Agriculture and livestock farming. It also includes most of the forestry land and hunting grounds. The transition zone is where most of the anthropogenic action occurs. Ensuring sustainable management of the territory is essential in this zone, because it is where traditional crops are grown around the villages, traditional architecture is preserved, and most of the tourism takes place.

The area is mountainous, with abrupt relief and altitudes ranging from 360 to $2425 \mathrm{~m}$. In addition to the mountain ranges (Sierra de Béjar and Sierra de Francia), it has pronounced valleys, such as those formed by the rivers Alagón, Tormes, Francia, Quilamas, Sangusín, and Cuerpo de Hombre. The differences in altitude, extensive hydrographic network, and varied climate conditions have created a wide variety of ecosystems, ranging from high mountain to riverside woodlands, including rocky 
areas and granite outcrops, peat bogs and woodland of tree species, notably holm oak, Pyrenean oak, Portuguese oak, sweet chestnut, strawberry tree, dehesa systems, ash, and pine. The main activity in the district is livestock farming, with traditional extensive farming practices, although arable farming has also played an important part in its human history and landscape formation, with traditional hillside terracing common in the area. Local relief and climate have determined the traditional architecture. The traditional mountain Mediterranean house has two main typologies: Stone houses and half-timbered buildings. Wooden framing has traditionally been used for the construction of the upper stories, away from moisture and xylophages, and masonry for the lower story as the mainstay of the entire building. Framing is limed in some buildings and visible in others, creating greater visual complexity (Figure 2) [34].

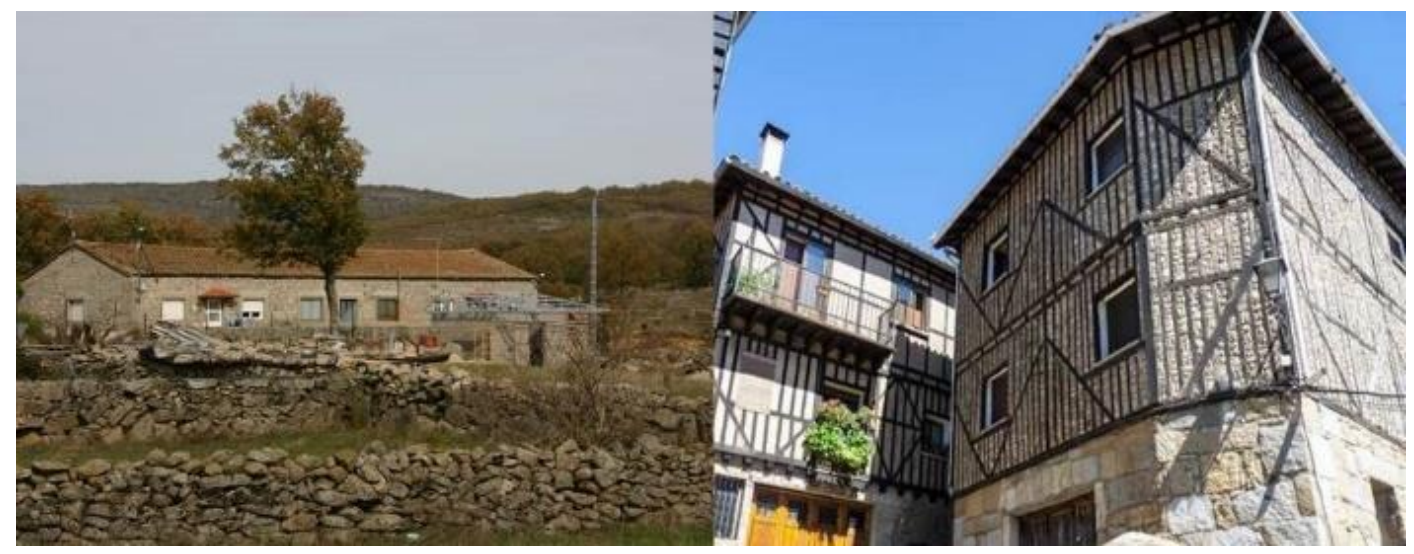

Figure 2. Traditional mountain Mediterranean houses.

Threats have been detected in all the municipalities of the reserve, and if they are not taken into consideration and acted on correctly, they could have adverse environmental and socioeconomic effects on the region. The most significant threats are neglect of residential areas, architectural heterogeneity, incomplete or unfinished town planning for the transition area, loss of land use or inappropriate use in the buffer zone, and large infrastructure and changes in dominance in the core zone.

\subsection{Information Gathering}

This study is part of a collaboration agreement funded by the Salmantina Association of Mountain Agriculture (ASAM). After an initial meeting with experts from the association and in a first phase of work, eight municipalities in the study area were proposed for participation. The selection criteria were:

- $\quad$ The natural and landscape context;

- A lack of unification of legal criteria in the aesthetic regulation of new buildings;

- $\quad$ Forecasts for increasing tourism in the medium term.

The eight municipalities chosen were La Calzada de Béjar (population 87), Navacarros (population 125), Lagunilla (population 549), Valero (population 361), Valdefuentes de Sangusín (population 257), Horcajo de Montemayor (population 170), Cepeda (population 400), and Sotoserrano (population 655).

In a second phase, within each municipality, criteria were defined for selecting the buildings for the case study.

Vegetation has been reported as the element with the most important role in the integration of building if designs show some impact related to scale, color or building materials [35], although these authors did not quantify the role of vegetation. Based on this work, all final buildings selected for the study complied with the following criteria:

- $\quad$ Not to be built in the style of local traditional architecture; 
- To be in a state of severe neglect;

- $\quad$ To be taller than the other dominant elements.

The fixation of these criteria allowed the subsequent statistic comparison of results among scenarios, avoiding mask results with other noisy variables not considered in this study such as color or texture variations effects.

In a third phase, extensive field work was carried out in the eight selected municipalities to locate test cases that met the criteria defined. Two municipalities (La Calzada de Béjar and Navacarros) were excluded because they had no potential cases.

For each selected case, a scoreboard was drawn up to gather the following data: Case number, coordinates, altitude, photos, vegetation, height, and width. The coordinates and altitude of buildings were determined using GPS Garmin Colorado 300. All photos were taken on a Canon 350D camera, and building height was measured using a VERTEX Laser Hypsometer. Photos were taken at distances and from angles that captured as many details of the selected buildings as possible. The distances considered suitable allowed for 30-50\% scene occupation by the building [36]. Unlike viewpoints with perspective, frontal viewpoints do not appear to have a negative impact on the visual analysis of a façade [37], and therefore, both types were used indiscriminately in the study photos. Photos were taken exclusively according to determining factors of accessibility and visibility of the building, from well-used roads or streets, keeping the direct line of observation as perpendicular as possible to the façades under study [38]. From each case, the most representative photo was chosen to determine the final cases for the study (Table 2).

Table 2. Final cases selected for the study. Superscript indicates the type of vegetation used: Tree (1) or climber (2).

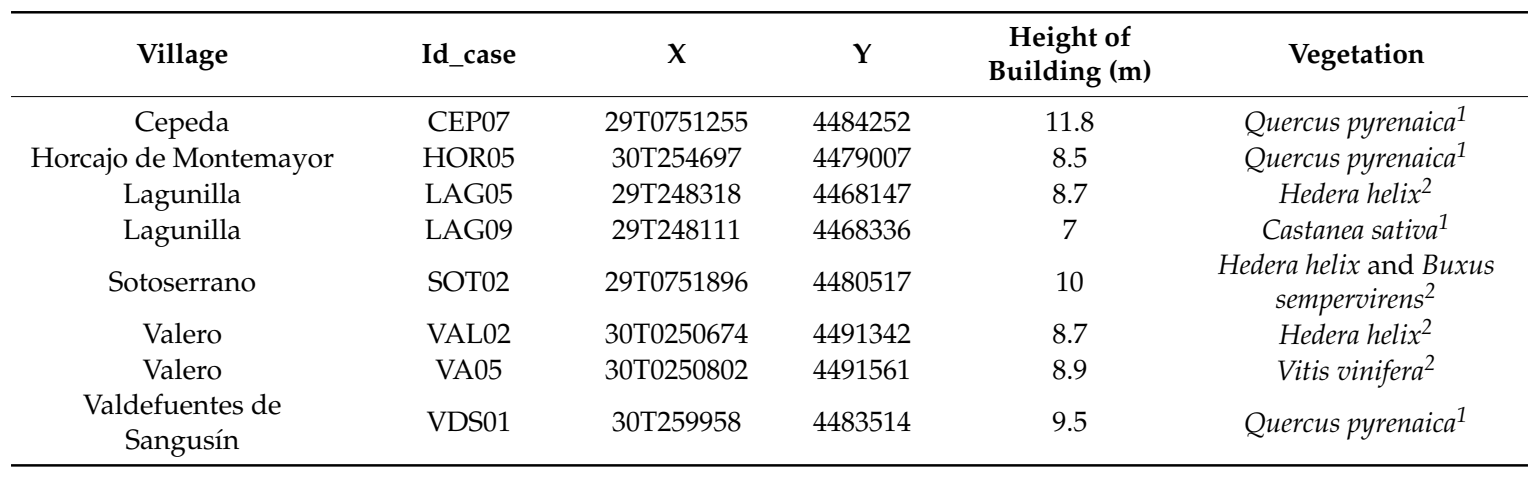

In a fourth phase, eight sets of three façade simulations were prepared, based on the eight buildings selected and three different degrees of vegetation filtering in the foreground. This generated 24 pictures for evaluating visual stimuli (Figure 3).

The thresholds for filtering modification were chosen as follows:

(1) No vegetation on the infograph, providing $0 \%$ filtering (real and control case). Expected to be the scenario worst evaluated by observers;

(2) Vegetation providing filtering of around $40-50 \%$;

(3) Vegetation providing maximum filtering of around $70-80 \%$. 
a) $\quad 0 \%$

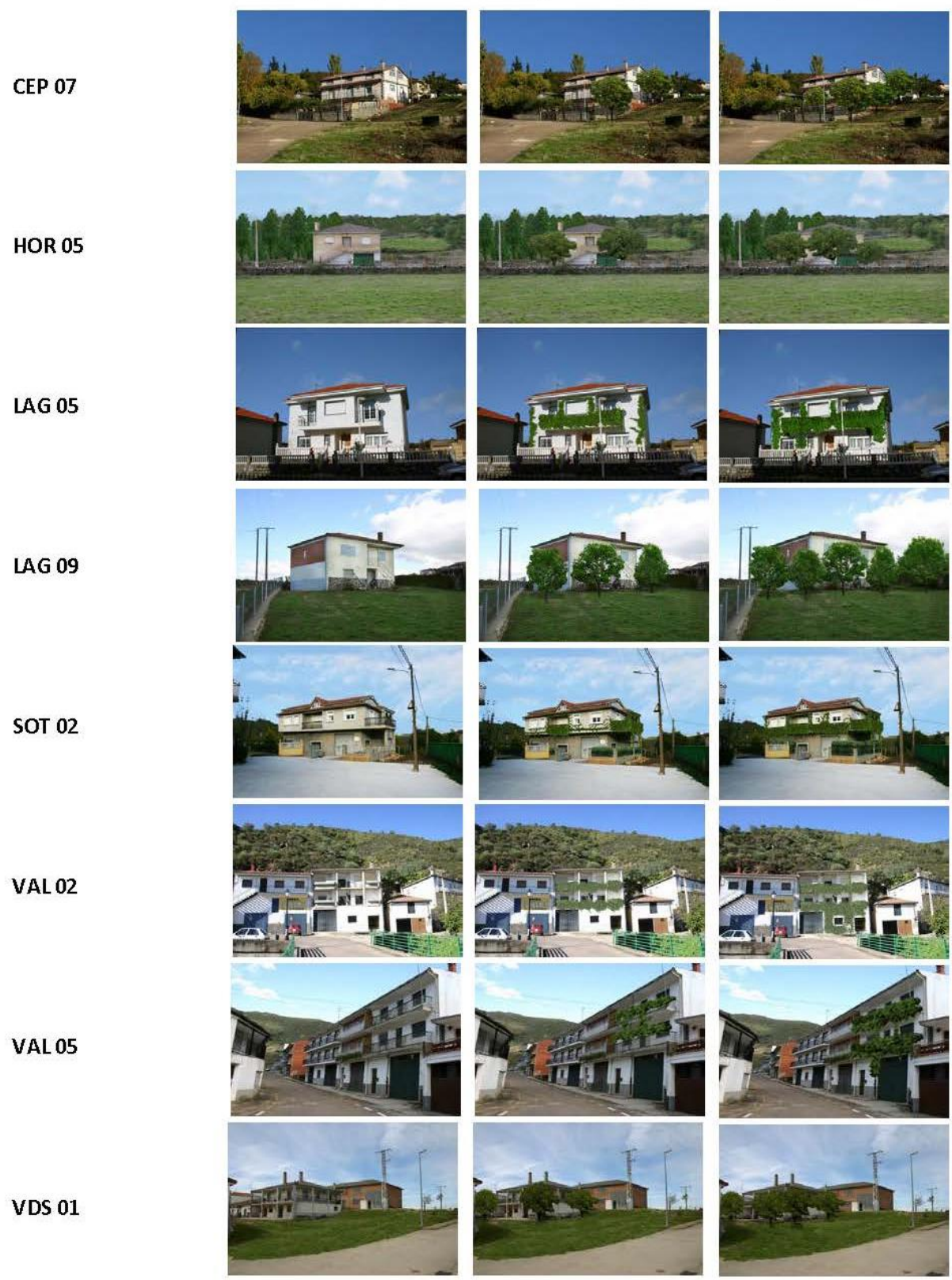

Figure 3. Thumbnails created using Adobe Photoshop CS5 ${ }^{\circledR}$ software, in which the vegetation produces: (a) Filtering of $0 \%$ in the left-hand column (real cases), (b) $40-50 \%$ in the middle column, and (c) maximum of $80 \%$ in the right-hand column.

Thresholds 2 and 3 were chosen based on other studies [31]. These authors proposed a methodology of filtering analysis of rural buildings according to concealment percentages by trees (a: $>80 \%$, b: $60-80 \%$, c: $60-20 \%, \mathrm{~d}:<20 \%)$. They considered sharpness of the contour lines of the building as a secondary variable closely related to the impact of color, concluding that the (b) and (c) thresholds had positive differences in the integration of buildings with high impact because of their design, like those in the present work, and threshold (b) was better than (c).

The diverse vegetation vs. building concealment percentages ranges of modification were laid out according to the Weber-Fechner Law (WFL) [39]. WFL describes the relationship between the magnitude of a physical stimulus and its perceived intensity and is considered to be an important principle in psychophysics. According to this principle, the sensory system is able to notice differences as soon as the basic physical stimulus changes for more than a constant proportion of its actual 
magnitude [40,41]. An expert panel, constituted by landscape architects, planners, geographers, and ecologists, performed a prior evaluation of different concealment percentages according to the WFL. Ratios of about $40-50 \%$ were found to render significant changes, and the following were selected for the study on the basis of it. Therefore, percentages within these ranges are those proposed for cases 2 and 3 of this present study.

To increase the statistical study by one variable, we decided to study two types of vegetation on the frontal plane: Trees (analyzed by other authors) and climbing plants (not reported in previous studies).

To define the 24 scenarios, three infographs were made for each case study by modifying the quantity of vegetation in the foreground of the building using Adobe Photoshop CS3 ${ }^{\circledR}$ software, without altering the composition of the original image. The infographs were modified by altering the percentage of filtering on the building produced by the vegetation. Climbing plants were used in four cases and tree species in the other four (Table 2). All species were native to the area. The percentage of filtering achieved by the vegetation was determined using Adobe Photoshop CS3 ${ }^{\circledR}$ software, Figure 4.

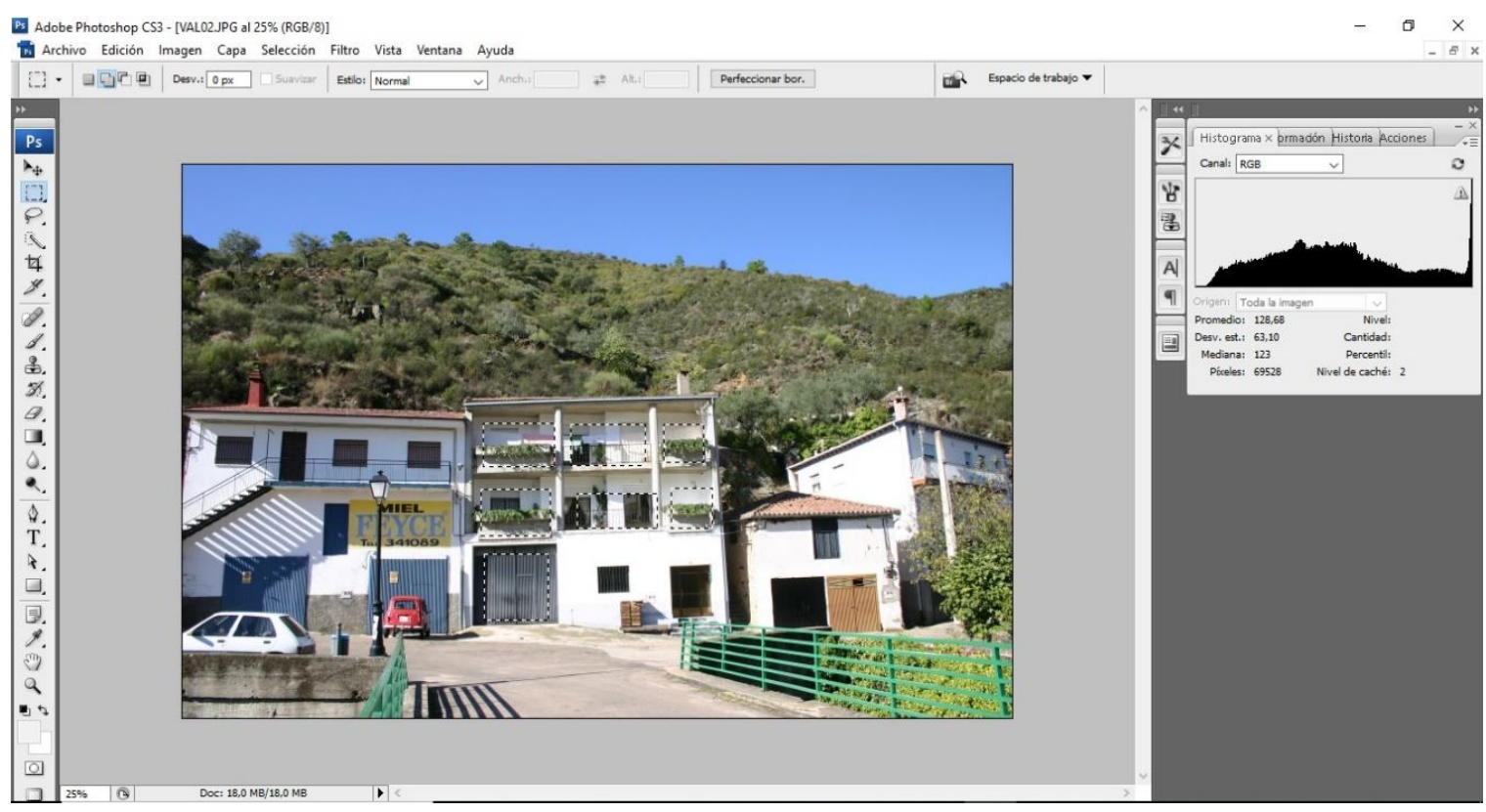

Figure 4. Procedure for calculating vegetation filtering with Adobe Photoshop CS ${ }^{\circledR}$.

\section{Materials and Methods}

\subsection{Selection of Participants}

University students have been proven to be a suitable group for analyzing visual façade preferences [42-44]. Other works have even demonstrated which students' assessment of visual quality is comparable to a general population valuation [45]. However, other previous researchers have found how local people compared to the general public could present some differences on landscape perception, since their familiarity with the context of scenarios polled could be affecting results [24], so the controversy remains open. In order to take into account these considerations, the survey conducted to evaluate visual acceptance of each scenario developed was performed in two groups of respondents: 27 local people from La Calzada de Béjar with no university studies, and 39 non-locals studying at the University of Extremadura who had no links to the municipalities. 


\subsection{Survey Preparation}

To compare possible results, a survey was conducted to analyze the visual integration of rural buildings to determine how varying the percentage of a building covered by vegetation screens can affect the visual perception and evaluation of the building in each scenario on respondents.

The 24 infographs were shown to respondents randomly so that the results would not be affected by the presentation order of the images $[44,46]$. On seeing each infograph, respondents had to evaluate the integration of the building in terms of visual preference using an ascending scale with 5 options from "Very poor" $=1$ to "Very good" $=5$. An ascending value scale is a simple and efficient measure of the hedonic tone of a respondent to a visual stimulus, as shown by other researchers [47,48], and is therefore considered suitable for the study objectives.

\subsection{Statistical Analysis}

Respondents' answers (RA) are the dependent variable of the study; their ascending ordinal nature permits continuous analysis of averages [49]. As well as the observed frequencies, the means of the respondents' preferences were determined for each photo. Vegetation type (VT) $(1=$ tree, $2=$ climber), percentage or degree of filtering $(\mathrm{PF})($ none $=0 \%$, medium $=40-50 \%$, high $=70-80 \%$ ), and respondent origin $(\mathrm{RO})(1=$ university student, $2=$ local $)$ are the independent variables or study factors. The aim was to analyze whether these factors carry weight in the dependent variable. Two statistical analyses were performed: (1) Repeated measures analysis of variance (rANOVA) and (2) frequency analysis using the chi-square test.

Analysis (1) allowed us to detect possible effects and interactions between the study factors and the variable response. The mean of the response was analyzed with a factorial ANOVA: $(V T(2) \times P F$ (3) $\times \mathrm{RO}(2)$ ). The first two variables are subject to an analysis of repeated measures (intra-subject analysis), while the respondent origin ( $\mathrm{RO}$ ) comprises inter-subject analysis (classic variance analysis).

Factors affecting responses with statistical weight were analyzed in depth by post hoc analysis (Bonferroni test). This makes it possible to locate where the significant differences arise within the categories of each factor and to detect, among other aspects, whether intermediate filtering percentages are significantly more poorly rated than high percentages or no vegetation. Possible interactions between factors (e.g., vegetation type and degree of filtering) can also be analyzed with this sort of test.

The effect size of significant results is also a very commonly used statistical indicator in visual impact studies. Cohen's $d$ measures the strength with which a phenomenon is produced. This indicates not only if two photos or scenarios have significant differences $(p<0.05)$, but also how different they are. For Cohen's $d$, an effect size up to 0.2 might be a "small" effect, around 0.5 a "medium" effect, and 0.8 to infinity a "large" effect; $\mathrm{d}>0.2$ is accepted as good threshold for distinguishing significant from non-significant differences in environmental visual assessment [50]. In analysis (2), the significant results obtained in (1) were applied to perform a frequency analysis using the Chi-square test. The results of the analyses are illustrated using frequency bar graphs or histograms. The two analyses are complementary.

\section{Results and Discussion}

All the field trips followed the same procedure of locating and photographing buildings that clashed with their urban or natural setting. The cases evaluated were residential buildings in urban settlements. Farm and industrial buildings and other building typologies beyond the built-up area were left for later studies. Buildings with poor access or visibility for correct photo capture were excluded (Figure 5). A total of 30 potential case studies were recorded. Cases analyzed in Horcajo de Montemayor are shown below as an example. 


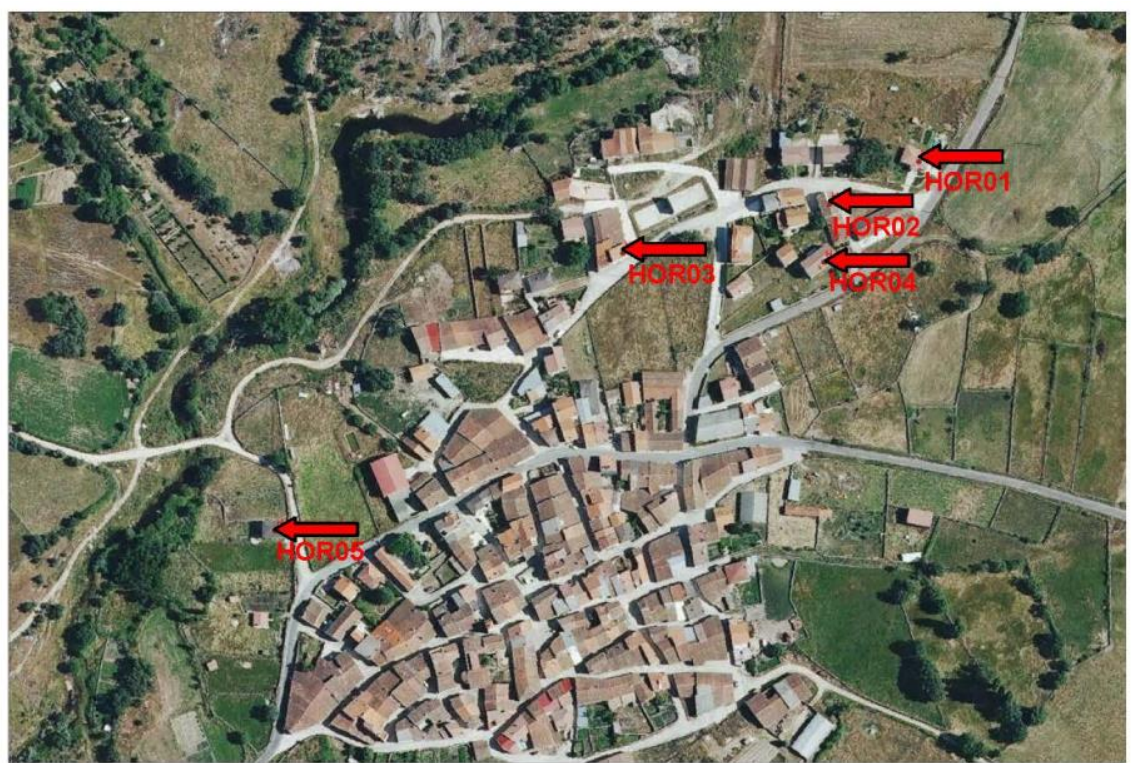

Case studies:

HOR01
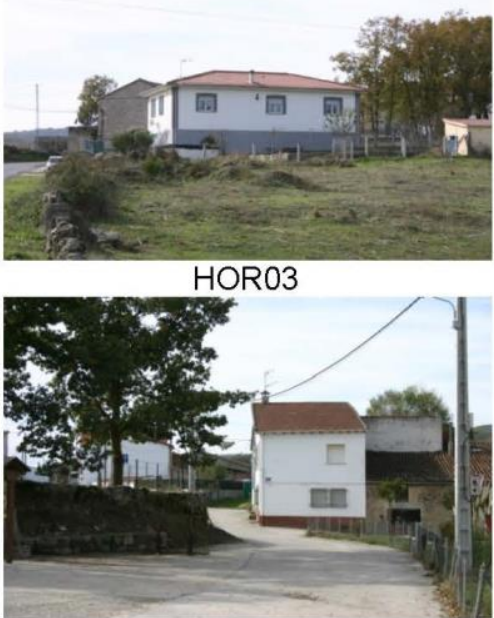

HOR05

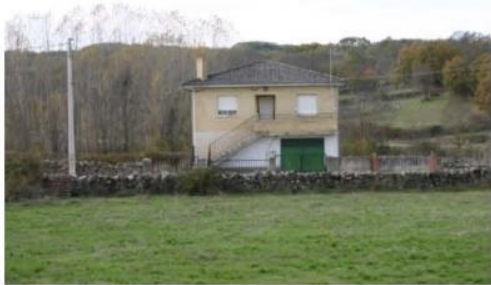

HORO2

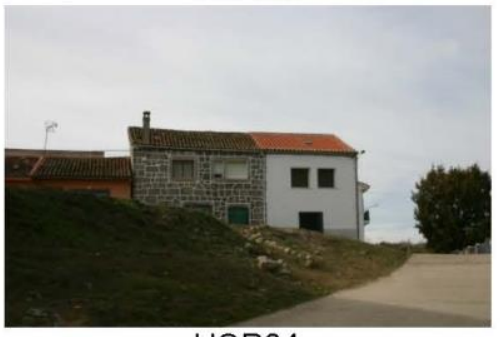

HORO4

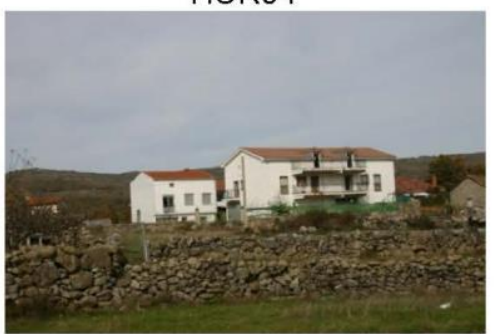

Figure 5. Location and case studies in Horcajo de Montemayor (Salamanca). Source: Own elaboration based on data from the National Geographic Institute.

From a total inventory of 30 cases, eight were selected at random. This initial number is considered high enough by other authors for subsequent modification of survey scenarios and statistical analysis $[35,42]$.

The percentage of filtering of each building was calculated by dividing the number of pixels occupied by vegetation on the façade by the total number of pixels of the façade. The filtering calculated in each infograph is shown in Table 3. 
Table 3. Summary of the filtering calculated in the 16 infographs generated from the eight real photos. Numeration comprises the identifier of each real case (Table 2) followed by 50 or 80 depending on the percentage of filtering applied.

\begin{tabular}{ccccc}
\hline Village & Case & Pixels Building & Pixels Vegetation & \% Filtering \\
\hline Valero & VAL02 50 & 214,182 & 111,509 & 52.06 \\
Valero & VAL02 80 & 214,182 & 168,162 & 78.51 \\
Lagunilla & LAG09 50 & 243,826 & 125,496 & 51.47 \\
Lagunilla & LAG09 80 & 243,826 & 191,219 & 78.42 \\
Horcajo & HOR05 50 & 48,683 & 22,162 & 45.52 \\
Horcajo & HOR05 80 & 48,683 & 35,994 & 73.94 \\
Valdefuentes & VDS01 50 & 79,467 & 35,736 & 44.97 \\
Valdefuentes & VDS01 80 & 79,467 & 59,370 & 74.71 \\
Valero & VAL05 50 & 135,648 & 76,424 & 56.34 \\
Valero & VAL05 80 & 135,648 & 101,015 & 74.47 \\
Sotoserrano & SOT02 50 & 105,378 & 48,868 & 46.37 \\
Sotoserrano & SOT02 80 & 105,378 & 76,020 & 72.14 \\
Lagunilla & LAG05 50 & 39,866 & 19,438 & 48.76 \\
Lagunilla & LAG05 80 & 39,866 & 31,930 & 80.09 \\
Cepeda & CEP05 50 & 65,953 & 28,522 & 43.25 \\
Cepeda & CEP05 80 & 65,953 & 54,426 & 82.52 \\
\hline
\end{tabular}

The repeated measures ANOVA results show that VT, PF, and RO have a significant main effect on the response. Therefore, on average, the presence of tree vegetation was more highly rated than the presence of climbing plants (Tree: $2.897(\mathrm{SE}=0.049)$, Climber: $2.603(\mathrm{SE}=0.056)$ ), degree of filtering was always valued more highly in ascending order (None $=0 \%: 2.133(\mathrm{SE}=0.088)$, Medium $=40-50 \%$ : $2.876(\mathrm{SE}=0.057)$, High $=70-80 \%: 3.240(\mathrm{SE}=0.077)$ ), and university students rated slightly better than locals (Students: 2.848 ( $\mathrm{SE}=0.061)$, Locals: $2.651(\mathrm{SE}=0.073)$ ).

However, no interactions were observed between RO and the study factors, VT and PF (Tables 4 and 5), indicating that even if the university students have a significant tendency to give a higher rating, the response pattern according to the degree of filtering and vegetation type is similar (Figure 6).

Table 4. Repeated measures ANOVA of within subject effects regarding percentage or degree of filtering (PF) and vegetation type (VT).

\begin{tabular}{|c|c|c|c|c|c|c|}
\hline Source & $\begin{array}{l}\text { Type III Sum of } \\
\text { Squares (SS) }\end{array}$ & df & $\begin{array}{l}\text { Mean Square } \\
\text { (MS) }\end{array}$ & $\mathbf{F}$ & Sig. ${ }^{1}$ & $\mathrm{~d}(\text { Cohen })^{2}$ \\
\hline $\mathrm{PF}$ & 81.237 & 2 & 40.618 & 63.739 & 0.000 & 1.996 \\
\hline Error (PF) & 81.569 & 128 & 0.637 & & & \\
\hline VT & 8.257 & 1 & 8.257 & 42.719 & 0.000 & 1.634 \\
\hline Error (VT) & 12.370 & 64 & 0.193 & & & \\
\hline $\mathrm{PF}^{\mathrm{x}} \mathrm{VT}$ & 3.275 & 2 & 1.637 & 13.147 & 0.000 & 0.906 \\
\hline Error $\left(\mathrm{PF}^{\mathrm{x}} \mathrm{VT}\right)$ & 15.941 & 128 & 0.125 & & & \\
\hline $\mathrm{PF}^{\mathrm{x}} \mathrm{RO}$ & 1.029 & 2 & 0.514 & 0.807 & 0.448 & 0.225 \\
\hline $\mathrm{VT}^{\mathrm{x}} \mathrm{RO}$ & 0.408 & 1 & 0.408 & 2.111 & 0.151 & 0.363 \\
\hline $\mathrm{PF}^{\mathrm{x}} \mathrm{VT}^{\mathrm{x}} \mathrm{RO}$ & 0.170 & 2 & 0.085 & 0.684 & 0.506 & 0.207 \\
\hline
\end{tabular}

${ }^{1}$ Significance level was set at 0.05 . PF, VT, and $\mathrm{PR}^{\mathrm{x}} \mathrm{VT}$ interaction presented significant effects on dependent variable (RA). ${ }^{2}$ Cohen's $d>0.8$ indicates that these differences are visually important with a large effect size. 
Table 5. Repeated measures ANOVA of within subject effects regard to respondent origin (RO).

\begin{tabular}{ccccccc}
\hline Source & $\begin{array}{c}\text { Type III Sum of } \\
\text { Squares (SS) }\end{array}$ & df & $\begin{array}{c}\text { Mean Square } \\
\text { (MS) }\end{array}$ & F & Sig. ${ }^{\mathbf{1}}$ & d (Cohen) $^{2}$ \\
\hline $\begin{array}{c}\text { Respondent_Origin (RO) } \\
\text { Error }\end{array}$ & 3717 & 1 & 3717 & 4311 & 0.042 & 0.519 \\
\hline
\end{tabular}

${ }^{1}$ Significance level was set at 0.05 . CO presented significant effects (alpha $\left.<0.05\right)$ on dependent variable (RA, respondents' answers). ${ }^{2}$ Cohen's $d$ around 0.5 indicates that these differences are visually important with a medium effect size.

This means that a global response pattern can be assumed, irrespective of origin and education level. Similar results were obtained by Coeterier [51] and Kongjian [52], assuming that familiarity with the scenarios viewed has a slightly negative effect on assessments by local people, although it is insufficient to affect the global response pattern of the remaining study variables.

From this point, respondent origin is assumed to be not relevant in the vegetation filtering analysis. However, filtering and vegetation type have a significant interacted effect, as shown in Figure 6 and Table 4.

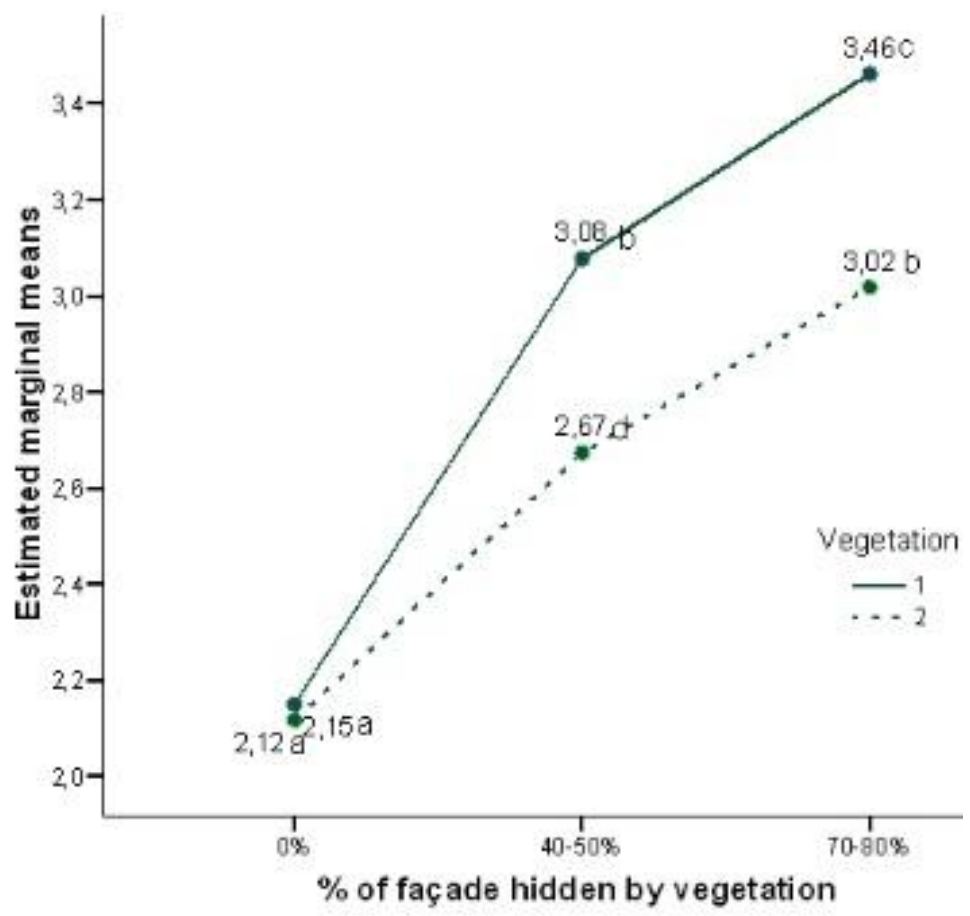

Figure 6. Interaction of means of Filtering $\times$ Vegetation. 1 = Tree; $2=$ Climbing plants. Different letters indicate significant differences; identical letters indicate similarity (Bonferroni test). (ANOVA data PF $^{\mathrm{x}}$ VT: $\left.\mathrm{F}[2.128]=13.15 ; p<<0.01 ; \mathrm{d}=0.906\right)$.

In addition to the higher evaluation of trees than climbers, the significant differences between degree of filtering are found only in phases $2(40-50 \%)$ and $3(70-80 \%)$ of plant coverage. This means that as the degree of filtering increases, differences in acceptation increase significantly, with the highest ratings occurring for buildings with a high filtering coverage $(70-80 \%)$ in both vegetation types (Figure 6). In phase 1 (no filtering), the response pattern is similar for both vegetation types, shown by the convergence of valuation means in Figure 6 . They are also the cases with the lowest value (2.1), or worst acceptance. Another interesting effect occurs on comparing the medium filtering means $(40-50 \%)$ of trees (3.08, Figure 6) with the high filtering means $(70-80 \%)$ of climbing plants $(3.02$, Figure 6). The values are statistically equal, close to score category $3=$ "acceptable". The interpretation of this result suggests that to achieve positive integrations higher than 3 on a scale from 1 to 5 , two combinations could be used: Trees with a medium filtering threshold or climbing plants that densify 
the façade to a high percentage. This information is relevant for town planning management, because plant type or species and the degree of filtering should not be combined at random, as shown in the results. Further research with other species could extend these results.

The effect size of the interrelation between VT and PF $(d=0.906$ Table 4$)$ is high enough $(d>0.8)$ to be taken into consideration. This enhances the relevance of this work, given that, with a relatively small sample of respondents $(n=66)$, considerable effects were obtained for filtering and vegetation type in front of a façade. Increasing the sample would not increase the significance level or give greater consistency to the results. Both variables (vegetation type and degree of filtering) thus have a considerable impact on the visual effect of a façade and could be generalized for any average respondent.

Related to the frequency analysis, the $\mathrm{Chi}^{2}$ test confirmed the paired differences between the five response types (Very poor to Very good) and the three degrees of plant density (Figure 7). These analyses no longer consider the effect of the respondent, in view of the rANOVA results. Thus, it is clear that if the entire façade is visible, the rating of the whole scenario drops. The best situation is when façade vegetation coverage is much higher than $50 \%$, regardless of vegetation type, although climbers have a lower overall rating (Figure 8).

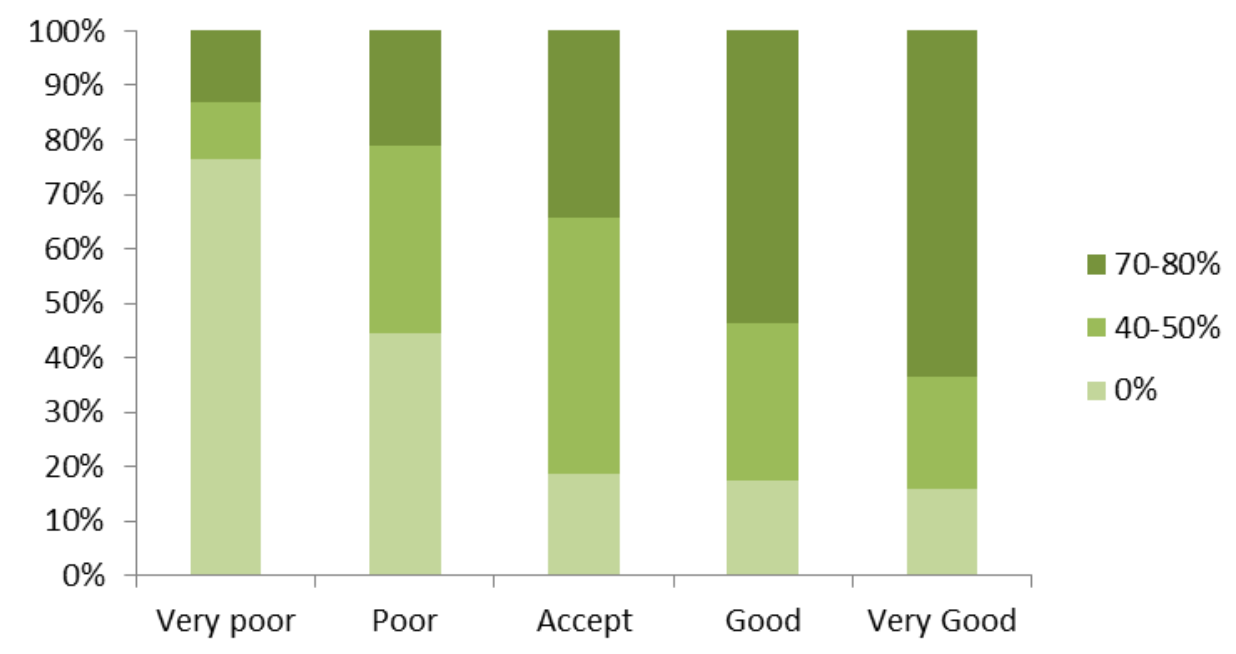

Figure 7. Percentage of total responses by degree of filtering $(\mathrm{PF})\left(\mathrm{Chi}^{2}[8,1584]=386.3 ; p<<0.01\right)$.

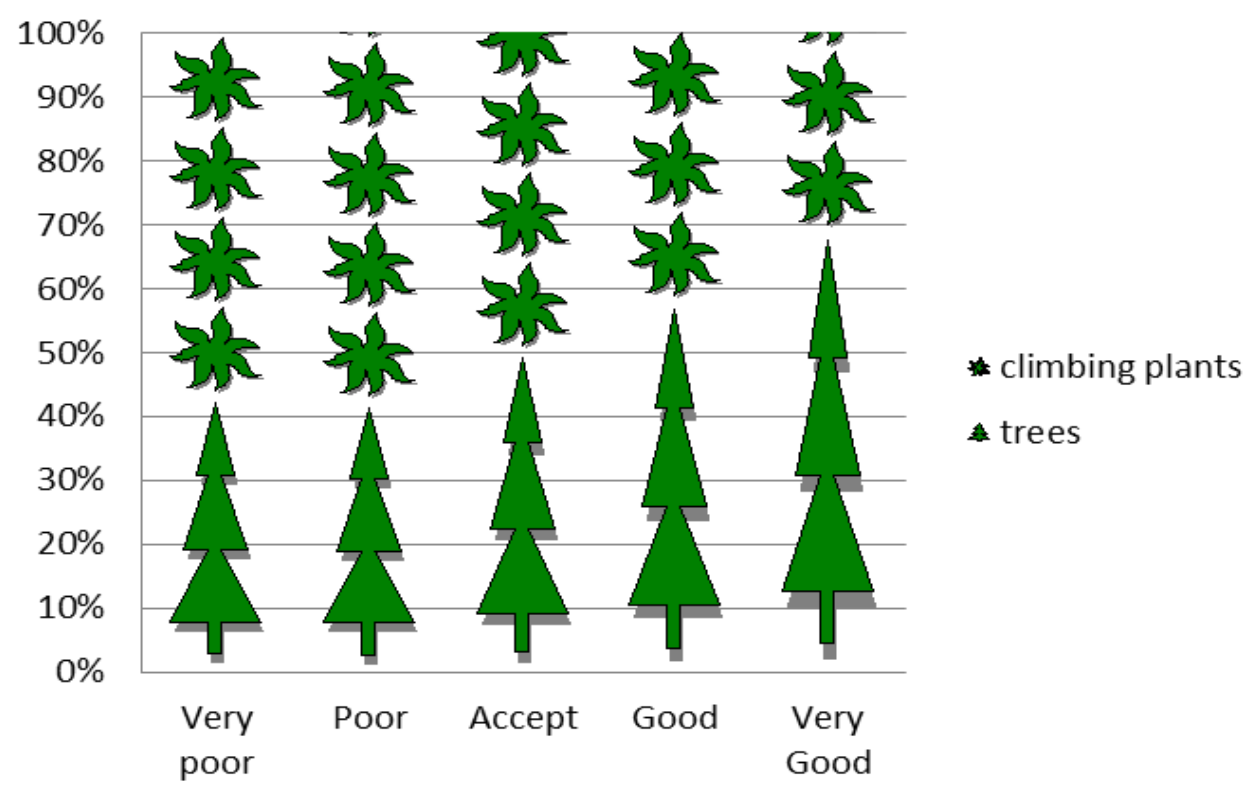

Figure 8. Response pattern by vegetation type (VT) $\left(\mathrm{Chi}^{2}[4,1584]=34.93 ; p<<0.01\right)$. 
Screening around this threshold (50\%) clearly increases the likelihood of finding ratings of at least "Acceptable" in the case of trees (Figure 9), although for climbers, plant coverage should once again be increased to $70-80 \%$ for good probabilities of acceptance (Figure 9 ).

a)

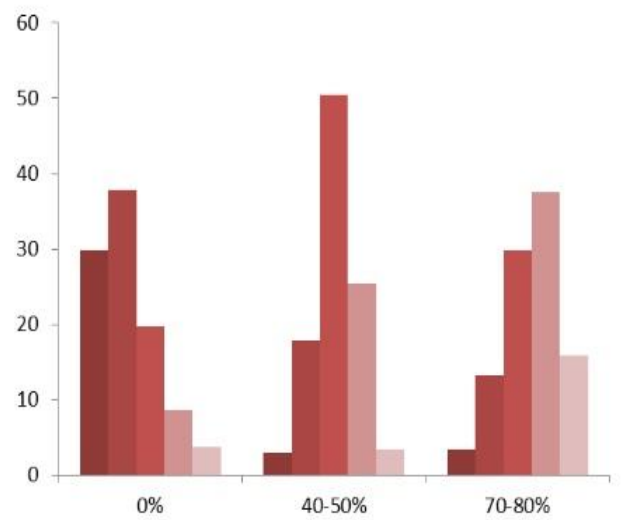

b)

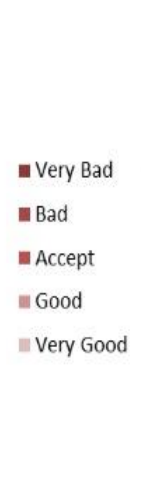

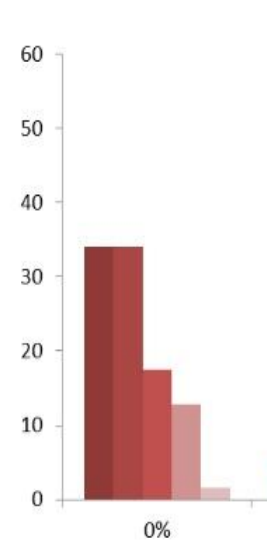

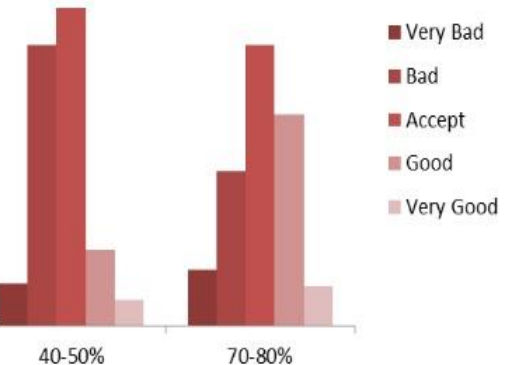

Figure 9. Responses by degrees of filtering and vegetation type: (a) Trees $\left(\mathrm{Chi}^{2}[8,792]=262.54 ; p<<\right.$ $0.01) ;$ (b) climbers $\left(\mathrm{Chi}^{2}[8,792]=162.53 ; p<<0.01\right)$.

Although some authors question the validity of the photographic method and express doubts about whether a photo can represent a complex scene and if it is possible to evaluate in the office attributes that are not perceptible via photos, such as sounds, smells and shades of color [53,54], most studies vouch for the usefulness of this technique in landscape assessment [55-61]. Moreover, infographic simulation from a photographed scene allows viewers to compare and evaluate a range of possible scenes [62-66]. Therefore, the experimental approach used in the present investigation can be defended as being valid and suitable.

\section{Conclusions}

The design of buildings targeted for improved integration could be enhanced by attention to detail in visual aspects linked to species type, plant density, and plant layout in the building's foreground, to achieve a determined filtering level. The conclusions and methodology of this study could assist in town planning design and landscape protection by proposing improvements with a scientific base, including recommendations on the type and form of vegetation screen depending on the purpose and the characteristics of new projects.

The main conclusions of this work on vegetation, based on the results, agree with the findings of other research groups working on similar projects. The practical, concrete nature of the study means that many of the conclusions can be used by architects, planners, designers, and technicians. The most important conclusions are:

(1) Using vegetation to filter the view of a building, in general terms and regardless of which species is used, enhances the integration of a project into the surroundings;

(2) Using vegetation with an intermediate degree of filtering in the frontal plane of a building $(40-50 \%)$ increases the possibility of the perception of the façade improving from Poor or Very poor to at least Acceptable;

(3) A higher percentage of filtering with vegetation (ca. 70-80\%), stopping short of total concealment, always improves evaluation, increasing the probability of the integration being rated Good or Very good.

Building integration is typically improved more by trees arranged as a screen than by climbing plants on the façade. 


\section{Future Lines}

- Future lines of research could be the incorporation of new native plant species, characteristic of riverine areas, in order to expand the study areas and scenarios considered. It is also possible to advance the method of conducting the surveys, looking for not only the public opinion, but also recording their behavior and attitude during the completion of them;

- Generate an interactive virtual environment that allows respondents to modify the modelled scenarios and different elements, in addition to allowing them to freely navigate inside the modeling space.

Author Contributions: Formal analysis, J.G.V., M.J.M.P., J.H.B. and L.G.M.; Funding acquisition, J.H.B. and L.G.M.; Investigation, J.G.V., M.J.M.P., J.H.B. and L.G.M.; Methodology, J.G.V., M.J.M.P., J.H.B. and L.G.M.; Project Administration, J.H.B.; Supervision, J.G.V, M.J.M.P., J.H.B. and L.G.M.; Writing-original draft, J.G.V. and J.H.B.; Writing-review \& editing, J.G.V., M.J.M.P., J.H.B. and L.G.M.

Funding: Publication of this article has been possible thanks to the collaboration agreement funded by the Salmantina Association of Mountain Agriculture (ASAM) and the funding of the Government of Extremadura and the European Regional Development Fund (ERDF), reference GR18176, granted to the research team INNOVA and reference GR18052, granted to the research team in Sustainable Development and Territorial Planning of the University of Extremadura.

Acknowledgments: Publication of this article has been possible thanks to the collaboration agreement funded by the Salmantina Association of Mountain Agriculture (ASAM) and the funding of the Government of Extremadura and the European Regional Development Fund (ERDF), reference GR18176, granted to the research team INNOVA and reference GR18052, granted to the research team in Sustainable Development and Territorial Planning of the University of Extremadura.

Conflicts of Interest: The authors declare no conflict of interest.

\section{References}

1. Van den Berg, A.; Vlek, C. The influence of planned-change context on the evaluation of natural landscapes. Landsc. Urban Plan. 1998, 43, 1-10. [CrossRef]

2. Schmid, W.A. The emerging role of visual resource assessment and visualisation in landscape planning in Switzerland. Landsc. Urban Plan. 2001, 54, 213-221. [CrossRef]

3. Tassinari, P.; Torreggiani, D.; Benni, S. Dealing with agriculture, environment and landscape in spatial planning, A discussion about the Italian case study. Land Use Policy 2013, 30, 739-747. [CrossRef]

4. Deffontaines, J.P.; Thenail, C.; Baudry, J. Agricultural systems and landscapes patterns: How can we build a relationship? Landsc. Urban Plan. 1995, 31, 3-10. [CrossRef]

5. Kaplan, A.; Taşkin, T.; Önenç, A. Assessing the Visual Quality of Rural and Urban-fringed Landscapes surrounding Livestock Farms. Biosyst. Eng. 2006, 95, 437-448. [CrossRef]

6. Howley, P.; Donoghue, C.O.; Hynes, S. Exploring public preferences for traditional farming landscapes. Landsc. Urban Plan. 2012, 104, 66-74. [CrossRef]

7. Ryan, R.L. Local perceptions and values for a midwestern river corridor. Landsc. Urban Plan. 1998, 42, 225-237. [CrossRef]

8. Hernández, J.; García, L.; Ayuga, F. Integration Methodologies for Visual Impact Assessment of Rural Buildings by Geographic Information Systems. Biosyst. Eng. 2004, 88, 255-263. [CrossRef]

9. Schroeder, H.W.; Cannon, W.N. The aesthetic contribution of trees to residential streets in Ohio towns. J. Arboric. 1983, 9, 237-243.

10. Serpa, A.; Muhar, A. Effects of plant size, texture and colour on spatial perception in public green areas-A cross-cultural study. Landsc. Urban Plan. 1996, 36, 19-25. [CrossRef]

11. Kuo, F.E. The role of arboriculture in a healthy social ecology. J. Arboric. 2003, 29, 148-155.

12. Todorova, A.; Asakawa, S.; Aikoh, T. Preferences for and attitudes towards street flowers and trees in Sapporo, Japan. Landsc. Urban Plan. 2004, 69, 403-416. [CrossRef]

13. Acar, C.; Acar, H.; Eroglŭ, E. Evaluation of ornamental plant resources to urban biodiversity and cultural changing: A case study of residential landscapes in Trabzon city (Turkey). Build. Environ. 2007, 42, $218-229$. [CrossRef] 
14. Holm, D. Thermal improvement by means of leaf-cover on external walls-A simulation model. Energy Build. 1989, 14, 19-30. [CrossRef]

15. Krishan, A. Climate Responsive Architecture: A Design Handbook for Energy Efficient Buildings; Tata McGraw-Hill Education: Noida, India, 2001.

16. Gómez-Muñoz, V.M.; Porta-Gándara, M.A.; Fernández, J.L. Effect of tree shades in urban planning in hot-arid climatic regions. Landsc. Urban Plan. 2010, 94, 149-157. [CrossRef]

17. Luttik, J. The value of trees, water and open space as reflected by house prices in the Netherlands. Landsc. Urban Plan. 2000, 48, 161-167. [CrossRef]

18. Smardon, R.C. Appraising the reliability of Visual Impact Assessment methods. In Proceedings of the National Conference on Applied Technique for Analysis and Management of the Visual Resource, Village, NV, USA, 23-25 April 1979.

19. García, L.; Hernández, J.; Ayuga, F. Analysis of the exterior colour of agroindustrial buildings: A computer aided approach to landscape integration. J. Environ. Manag. 2003, 69, 93-104. [CrossRef]

20. Hernández, J.; García, L.; Ayuga, F. Assessment of the visual impact made on the landscape by new buildings: A methodology for site selection. Landsc. Urban Plan. 2004, 68, 15-28. [CrossRef]

21. Smardon, R.C. Perception and Aesthetics of the Urban Environment: Review of the Role of Vegetation. Landsc. Urban Plan. 1988, 15, 85-106. [CrossRef]

22. Purcell, A.T.; Lamb, R.J. Preference and naturalness: An ecological approach. Landsc. Urban Plan. 1998, 42, 57-66. [CrossRef]

23. Arriaza, M.; Cañas-Ortega, J.F.; Cañas-Madueño, J.A.; Ruiz-Avilés, P. Assessing the visual quality of rural landscapes. Landsc. Urban Plan. 2004, 69, 115-125. [CrossRef]

24. Rogge, E.; Nevens, F.; Gulinck, H. Perception of rural landscapes in Flanders: Looking beyond aesthetics. Landsc. Urban Plan. 2007, 82, 159-174. [CrossRef]

25. Lewis, P. Three-dimensional plant modelling for remote sensing simulation studies using the Botanical Plant Modelling System. Agronomie 1999, 19, 185-210. [CrossRef]

26. Lynch, J.A.; Gimblett, H.R. Perceptual values in the cultural landscape: A spatial model for assessing and mapping perceived mystery in rural environments. Comput. Environ. Urban 1992, 16, 453-471. [CrossRef]

27. Gimblett, H.R. Environmental cognition: The prediction of preference in rural Indiana. J. Archit. Plan. Res. 1990, 7, 222-234.

28. Stamps, A.E., III. Mystery, complexity, legibility and coherence: A meta-analysis. J. Environ. Psychol. 2004, 24, 1-16. [CrossRef]

29. Ikemy, M. The effects of mystery on preference for residential façades. J. Environ. Psychol. 2005, 25, 167-173. [CrossRef]

30. Tveit, M.; Ode, A.; Fry, G. Key Concepts in a Framework for Analysing Visual Landscape Character. Landsc. Res. 2006, 31, 229-255. [CrossRef]

31. García, L.; Montero-Parejo, M.J.; Hernández-Blanco, J.; López-Casares, S. Analysis of lines and forms in buildings to rural landscape integration. Span. J. Agric. Res. 2010, 8, 833-847. [CrossRef]

32. Hernández Blanco, J.; García Moruno, L.; Morán, J.; Juan, A.; Ayuga, F. Estimating visual perception of rural landscapes using GIS, the influence of vegetation. J. Food Agric. Environ. 2003, 1, 139-141.

33. Muhar, A. Three-dimensional modelling and visualisation of vegetation for landscape simulation. Landsc. Urban Plan. 2001, 54, 5-17. [CrossRef]

34. García Mercadal, F. La Casa Popular en España; Gustavo Gili: Paris, France, 1981.

35. Montero-Parejo, M.J.; García-Moruno, L.; López-Casares, S.; Hernández-Blanco, J. Visual impact assessment of color and scale of building on the rural landscape. Environ. Eng. Manag. J. 2016, 15, 1537-1550. [CrossRef]

36. Montero-Parejo, M.J.; García-Moruno, L.; Hernández-Blanco, J.; Casares-López, S. Analysis of lines and forms of agroindustrial buildings: A photo-analytical approach to landscape integration. In Agricultural and Biosystems Engineering for a Sustainable World, Proceedings of the International Conference on Agricultural Engineering, Hersonissos, Crete, Greece, 23-25 June 2008; European Society of Agricultural Engineers: Silsoe, UK, 2008.

37. Stamps, A.E., III. Simulation effects on environmental preferences. J. Environ. Manag. 1993, 38, 115-132. [CrossRef]

38. Herzog, T.R.; Shier, R.L. Complexity, age, and building preference. Environ. Behav. 2000, 32, 557-575. [CrossRef] 
39. Nasar, J.L.; Stamps, A.E., III. Infill McMansions: Style and the psychophysics of size. J. Environ. Psychol. 2009, 29, 110-123. [CrossRef]

40. Weber, E.H. De Pulsu, Resorptione, Auditu Et Tactu. Annotationes Anatomicae et Physiologicae; Koehler: Leipzig, Germany, 1834.

41. Reichl, P.; Egger, S.; Schatz, R.; D'Alconzo, A. The logarithmic nature of QoE and the Role of the Weber-Fechner Law in QoE assessment. In Proceedings of the 2010 IEEE International Conference on Communications, Cape Town, South Africa, 23-27 May 2010.

42. Stamps, A.E., III. Physical determinants of preferences for residential façades. Environ. Behav. 1999, 31, 723-751. [CrossRef]

43. Akalin, A.; Yildirim, K.; Wilson, C.; Kilicoglu, O. Architecture and engineering students' evaluations of house façades: Preference, complexity and impressiveness. J. Environ. Psychol. 2009, 29, 124-132. [CrossRef]

44. Imamoglu, Ç. Complexity, liking and familiarity, architecture and non-architecture Turkish students' assessments of traditional and modern house facades. J. Environ. Psychol. 2000, 20, 5-16. [CrossRef]

45. Yao, Y.; Zhu, X.; Xu, Y.; Yanf, H.; Wu, X.; Li, Y.; Zhanf, Y. Assessing the visual quality of green landscaping in rural residential areas: The case of Changzhou, China. Environ. Monit. Assess. 2012, 184, 951-967. [CrossRef]

46. Garrido-Velarde, J.; Montero-Parejo, M.J.; Hernández-Blanco, J.; García-Moruno, L. Visual analysis of the height ratio between building and background vegetation. Two rural cases of study: Spain and Sweden. Sustainability 2018, 10, 2593. [CrossRef]

47. Nasar, J.L. Adult viewers' preferences in residential scenes: A study of the relationship of the environmental attributes to preference. Environ. Behav. 1983, 15, 589-614. [CrossRef]

48. Garrido-Velarde, J.; Montero-Parejo, M.J.; Hernández-Blanco, J.; García-Moruno, L. Use of video and 3D scenario visualisation to rate vegetation screens for integrating buildings into the landscape. Sustainability 2017, 9, 1102.

49. Kendrick, J. Social Statistics, an Introduction to Using SPSS, 2nd ed.; Allyn and Bacon: Boston, MA, USA, 2005.

50. Stamps, A.E., III. A paradigm for distinguishing significant from non-significant visual impacts: Theory, implementation, case histories. Environ. Impact Assess. Rev. 1997, 17, 249-293. [CrossRef]

51. Coeterier, J. Lay people's evaluation of historic sites. Landsc. Urban Plan. 2002, 59, 111-123. [CrossRef]

52. Kongjian, Y. Cultural variations in landscape preference: Comparisons among Chinese sub-groups and Western design experts. Landsc. Urban Plan. 1995, 32, 107-126.

53. Kroh, D.P.; Gimblett, R.H. Comparing live experience with pictures in articulating landscape preference. Landsc. Res. 1992, 17, 58-69. [CrossRef]

54. Palmer, J.F.; Hoffman, R.E. Rating reliability and representation validity in scenic landscape assessments. Landsc. Urban Plan. 2001, 54, 149-161. [CrossRef]

55. Dunn, M.C. Landscape with photographs: Testing the preference approach to landscape evaluation. J. Environ. Manag. 1976, 4, 15-26.

56. Shafer, L.; Brush, R.O. How to measure preferences for photographs of natural landscapes. Landsc. Plan. 1977, 4, 237-256. [CrossRef]

57. Shuttleworth, S. The use of photographs as an environmental presentation medium in landscape studies. J. Environ. Manag. 1980, 11, 61-76.

58. Stewart, T.R.; Middleton, P.; Downton, M.; Ely, D. Judgments of photographs vs. field observations in studies of perception and judgment of the visual environment. J. Environ. Psychol. 1984, 4, 283-302. [CrossRef]

59. Hull, R.B.; Stewart, W.P. Validity of photo-based scenic beauty judgments. J. Environ. Psychol. 1992, 12, 101-114. [CrossRef]

60. Wherrett, J.R. Creating landscape preference models using internet survey techniques. Landsc. Res. 2000, 25, 79-96. [CrossRef]

61. Pérez, J.G. Ascertaining landscape perceptions and preferences with pair-wise photographs, planning rural tourism in Extremadura, Spain. Landsc. Res. 2002, 27, 297-308. [CrossRef]

62. Bishop, I.D.; Leahy, P.N.A. Assessing the visual impact of development proposals: The validity of computer simulations. Landscape 1989, 8, 92-100. [CrossRef]

63. Tress, B.; Tress, G. Scenario visualisation for participatory landscape planning-A study from Denmark. Landsc. Urban Plan. 2003, 64, 161-178. [CrossRef]

64. García, L.; Hernández, J.; Ayuga, F. Analysis of the materials and exterior texture of agro-industrial buildings: A photo-analytical approach to landscape integration. Landsc. Urban Plan. 2006, 74, 110-124. [CrossRef] 
65. Dockerty, T.; Lovett, A.; Appleton, K.; Bone, A.; Sünnenberg, G. Developing scenarios and visualisations to illustrate potential policy and climatic influences on future agricultural landscapes. Agric. Ecosyst. Environ. 2006, 114, 103-120. [CrossRef]

66. Ghadirian, P.; Bishop, I.D. Integration of augmented reality and GIS: A new approach to realistic landscape visualization. Landsc. Urban Plan. 2008, 86, 226-232. [CrossRef]

(C) 2019 by the authors. Licensee MDPI, Basel, Switzerland. This article is an open access article distributed under the terms and conditions of the Creative Commons Attribution (CC BY) license (http://creativecommons.org/licenses/by/4.0/). 